\title{
Hypertensive diseases in pregnancy and breast cancer risk
}

\author{
S Opdahl',', PR Romundstad', MDK Alsaker ${ }^{1,2}$ and LJ Vatten' \\ 'Department of Public Health and Community Medicine, Faculty of Medicine, Norwegian University of Science and Technology, NTNU, Postbox 8905, \\ MTFS, Trondheim N-749I, Norway; ${ }^{2}$ Department of Oncology, St Olavs Hospital, Trondheim N-7006, Nonway
}

\begin{abstract}
BACKGROUND: Hypertensive diseases in pregnancy may be associated with a reduced risk of breast cancer. Most previous studies are small and have shown conflicting results.

METHODS: In a cohort of 919712 women who gave their first birth between 1967 and 2008, with linkage of information from two national registries, we assessed whether women with pregnancy hypertensive diseases are at reduced breast cancer risk. We used Cox regression to estimate hazard ratios (HRs) with $95 \%$ confidence intervals $(\mathrm{Cl})$.

RESULTS: Compared with women with a normotensive first pregnancy, women with hypertension or preeclampsia in their first pregnancy had a reduced breast cancer risk (HR 0.83, 95\% Cl 0.77, 0.90). A reduced risk was consistently observed for hypertensive disease in any pregnancy, for recurrent hypertensive disease in pregnancy, and before and after 50 years of age at breast cancer diagnosis. The association was strongest for women with hypertension in pregnancy, who delivered at term/post-term (HR 0.8I, 95\% $\mathrm{Cl} 0.75,0.88$ ) or had a child of average birth weight (HR 0.77, 95\% Cl 0.69, 0.85).

CONCLUSION: Women with pregnancy hypertensive diseases are at reduced breast cancer risk. Whether this association can be attributed to pregnancy-specific events or to underlying biological traits remains unclear.

British Journal of Cancer (2012) 107, 176-182. doi:10.1038/bjc.2012.195 www.bjcancer.com
\end{abstract}

Published online 10 May 2012

(c) 2012 Cancer Research UK

Keywords: breast cancer risk; pregnancy; hypertension in pregnancy; preeclampsia; epidemiology; national registries

Pregnancy is associated with a long-term reduction in breast cancer risk (Kelsey et al, 1993). The underlying mechanisms are not fully understood, but the reduced risk has been attributed to the differentiation of breast tissue cells induced by pregnancy hormones (Britt et al, 2007). To improve our understanding of the role of pregnancy in breast cancer development, some investigators have studied long-term effects of certain pregnancy characteristics or complications (Nechuta et al, 2010), including hypertensive disorders in pregnancy such as preeclampsia and gestational hypertension.

Preeclampsia is clinically characterised by hypertension and proteinuria in the second half of pregnancy, and occurs in about $5 \%$ of primiparous women (Trogstad et al, 2011). Gestational hypertension and preeclampsia appear to be closely related conditions that may originate from the same underlying disorder (Villar et al, 2006). Studies that have examined the association of preeclampsia and/or hypertension in pregnancy with later breast cancer risk have shown conflicting results and variously reported reduced risk (Polednak and Janerich, 1983; Thompson et al, 1989; Troisi et al, 1998; Cohn et al, 2001; Vatten et al, 2002a, 2007; Innes and Byers, 2004; Terry et al, 2007), no association (Mogren et al, 2001; Cnattingius et al, 2005; Ma et al, 2010), or an increased risk (Talamini et al, 1997; Calderon-Margalit et al, 2009). Limitations of most previous studies include a relatively young age of the participants and a small number of exposed women who have later developed breast cancer.

It is not known whether an association of hypertensive diseases in pregnancy with later breast cancer risk may be attributed to

*Correspondence: Dr S Opdahl; E-mail: signe.opdah|@ntnu.no Received 20 February 2012; revised 12 April 2012; accepted 14 April 2012; published online 10 May 2012 events during that particular pregnancy, or to underlying traits that are both associated with susceptibility to pregnancy hypertension and with breast cancer risk (Innes and Byers, 1999; Nechuta et al, 2010). If the association of pregnancy hypertensive diseases with breast cancer risk differs depending on offspring sex (Terry et al, 2007; Troisi et al, 2007; Vatten et al, 2007), on the number of hypertensive pregnancies (Terry et al, 2007), or on the severity of the hypertensive condition (Vatten et al, 2002a; Terry et al, 2007), this may support a pregnancy-specific effect.

We have updated and extended the Norwegian data (Vatten et al, 2002a; Vatten et al, 2007) with an addition of 218706 participants and 6696 breast cancer cases, based on a linkage between the Medical Birth Registry of Norway and the Cancer Registry of Norway, and investigated the association of hypertensive diseases in pregnancy with later breast cancer risk. The increased statistical power enabled us to obtain more precise estimates for the previously reported associations. In addition, we have investigated whether the association is similar for hypertensive diseases in the first and in any pregnancy, whether the association could be modified by subgroup or severity of hypertensive disease, and whether a dose-risk association could be present, as indicated by the recurrence of hypertensive disease in pregnancy.

\section{METHODS}

\section{Study population}

Data were obtained from the Medical Birth Registry of Norway and the Cancer Registry of Norway. In the Medical Birth Registry, information on all births has been collected since 1967, and recorded in a standardised notification form completed by midwives and doctors. A total of 972331 women who gave their first birth between 1 January 1967 and 31 December 2008, and had 
singleton births only, were eligible for follow-up. We excluded 96 women who were diagnosed with breast cancer before their first birth and 2481 women who had a period of emigration before their first birth, and thus could not be followed for breast cancer occurrence before their first birth. We also excluded 50042 women (5\%) with missing information on the following factors related to their first pregnancy: duration of pregnancy, offspring sex, and offspring birth weight. The remaining 919712 women were followed for breast cancer occurrence.

\section{Study factors}

During the study period (1967-2008), nearly $100 \%$ of pregnant women in Norway have attended the publicly financed routine antenatal care (Backe, 1992). At each visit, blood pressure is measured and urine is examined for protein. Information from these visits and from medical examinations at the delivery unit is included in the notification form that is sent to the Medical Birth Registry. Hypertensive diseases in pregnancy are classified according to the International Classification of Diseases (ICD): ICD-8 was used throughout 1998, and ICD-10 from 1999. Hypertensive diseases in pregnancy were defined as hypertension in pregnancy (ICD-8: 637.0 and 637.2, ICD-10: O16) and as preeclampsia/eclampsia (ICD-8: 637.4-9, ICD-10: O13, O14 and O15; NIPH, 2009).

From the Medical Birth Registry, we also obtained information on the following factors: date of delivery, age at first birth, total number of pregnancies, offspring's birth weight in grams, offspring sex, and duration of pregnancy in completed weeks (based on ultrasound examination in $24 \%$ of the pregnancies and on the first day of the last menstrual period in $76 \%$ ).

\section{Follow-up}

The unique identification number of Norwegian citizens was used to link information from the Medical Birth Registry to information on cancer occurrence from the Cancer Registry of Norway, which also includes information on vital status and emigration, as recorded by the Population Registry at Statistics Norway. Invasive breast cancer was registered according to the ICD, 7th edition (ICD-7, code 170). Breast cancer diagnoses were based on histological $(99.4 \%)$, cytological $(0.5 \%)$, or clinical $(0.1 \%)$ examination. Reporting of new diagnoses of cancer to the Cancer Registry is mandatory by law, and follow-up for breast cancer is considered practically complete (Larsen et al, 2007). Women were followed from their first birth until the date of breast cancer diagnosis, death, emigration, or until 31 December 2008, whichever came first.

The study was approved by the regional committee for medical research ethics.

\section{Statistical analyses}

The association of hypertensive diseases in pregnancy with breast cancer incidence was assessed using the Cox proportional hazards models to estimate hazard ratios (HRs) with $95 \%$ confidence intervals (CI). We studied the association of preeclampsia/eclampsia (PE) and hypertension (HIP) in a woman's first pregnancy with breast cancer risk, both using PE and HIP combined, and as separate entities. We also investigated whether PE/HIP in any pregnancy was associated with the risk of breast cancer, where women contributed person-time to the exposed category from their first registered PE/HIP pregnancy. Among women with two or more births, we also investigated the association of $\mathrm{PE} / \mathrm{HIP}$ in the first or second pregnancy, and in both pregnancies.

To investigate whether the association could vary by menopausal status at diagnosis, we conducted separate analyses with follow-up until 50 years of age ( $<50$ years) and beyond 50 years $(\geqslant 50$ years), using 50 years as a crude indicator for menopausal status. We also conducted a sensitivity analysis for women followed from 60 years of age. Also, we studied whether the association of PE/HIP in the first pregnancy could be modified by duration of pregnancy ( $<37$ or $\geqslant 37$ weeks), offspring birth weight $(<3000,3000-3999$ or $\geqslant 4000 \mathrm{~g})$, and by offspring sex.

In a separate analysis, we studied whether the duration of a woman's first pregnancy was associated with breast cancer risk, stratified by whether PE/HIP occurred or not in the first pregnancy. The aim of this analysis was to clarify the role of preterm birth for the association of PE/HIP with breast cancer risk. Analyses of trend were performed by scoring each category of duration of pregnancy with the median value within that category. In the analysis, the categories were treated as a continuous variable, and we estimated HRs with 95\% CI per week of longer duration of pregnancy.

For all analyses, attained age was used as the time scale. We adjusted for maternal birth year (in 5-year categories), age at first birth $(<20,20-24,25-29,30-34$, or $\geqslant 35$ years), parity $(1,2,3,4$, or $\geqslant 5$ ), and marital status at first birth (married/cohabiting or single). Parity was treated as a time-dependent variable; thus, a woman entered a category of higher parity whenever a new birth occurred. We assessed heterogeneity of the HRs across strata of the different pregnancy characteristics by likelihood ratio tests, and compared models with and without product terms.

Proportionality between hazards was checked by comparing log minus log plots of survival and by performing tests based on Schoenfeld residuals. Assumptions were met for all the previously described models. In a sensitivity analysis, we investigated whether inclusion of women with missing information on offspring birth weight and sex, and duration of pregnancy, could alter the main results.

All analyses were conducted using Stata version 11.1 MP for Windows (Stata Corp., College Station, TX, USA).

\section{RESULTS}

A total of 919712 women without breast cancer at baseline were followed for approximately 19 million person years. Median time of follow-up was 20.4 years (interquartile range (IQR) 10.0-31.8 years) for women with a normotensive first pregnancy, and 17.8 (IQR 7.7-28.7 years) for women with PE/HIP in the first pregnancy. The difference in follow-up time was largely explained by an increase in the frequency of PE/HIP during the observation period. During follow-up, 15856 women were diagnosed with invasive breast cancer. Mean age at diagnosis was similar in the two groups (49.0 years, s.d. 8.4 years). Women with PE/HIP in their first pregnancy were older at first birth, had pregnancies of shorter duration, their children were smaller, and there was a higher proportion of male offspring after PE/HIP compared with normotensive first pregnancies. Characteristics of the study participants are shown in Table 1.

Women who had a hypertensive disease in their first pregnancy were at $17 \%$ lower risk of breast cancer than women with a normotensive first pregnancy (HR 0.83, 95\% CI 0.77, 0.90; Table 2). The lower risk was present both for isolated hypertension (HR $0.78,95 \%$ CI $0.68,0.89$ ) and for PE (HR 0.86, 95\% CI 0.79, 0.94). Estimates were similar for women who had PE/HIP in the first and second pregnancy (HR $0.84,95 \%$ CI $0.70,1.01$ ) and for women with PE/HIP in any pregnancy (HR $0.84,95 \%$ CI $0.79,0.89$ ). The associations were similar for breast cancer diagnosed before and after 50 years of age (Table 3), and for women 60 years and older (results not shown).

Tables 4 and 5 show associations of PE/HIP in first pregnancy according to pregnancy characteristics and offspring sex. There was no evidence for a stronger association related to the severity of hypertension, as indicated by preterm birth or low offspring birth weight. In fact, the association was more pronounced among women with average offspring birth weight (HR $0.77,95 \%$ CI 0.69 , $0.85)$, and the negative association was restricted to women who 
gave birth after 37 completed weeks of pregnancy (HR 0.81, 95\% CI $0.75,0.88)$. Overall, women with PE/HIP in their first pregnancy were at reduced risk of breast cancer, regardless of whether their

Table I Characteristics of the study participants, according to presence or absence of hypertensive disease in first pregnancy

\begin{tabular}{|c|c|c|}
\hline & Normotensive & PE/HIP \\
\hline Median time in study (IQR) & $20.4(\mid 0.0-31.8)$ & $17.8(7.7-28.7)$ \\
\hline $\begin{array}{l}\text { Mean age at breast cancer diagnosis } \\
\text { (s.d.) }\end{array}$ & $49.0(8.4)$ & $48.9(8.8)$ \\
\hline Median birth year (IQR) & $1962(|953-197|)$ & $1964(1955-1973)$ \\
\hline $\begin{array}{l}\text { Age at first birth, years } \\
\quad<20 \\
20-24 \\
25-29 \\
30-34 \\
\geqslant 35\end{array}$ & $\begin{array}{c}107734(12.5) \\
341394(39.5) \\
274815(31.8) \\
107038(12.4) \\
32341(3.7)\end{array}$ & $\begin{aligned} & 5595(9.9) \\
& 20329(36.0) \\
& 18853(33.4) \\
& 8352(14.8) \\
& 3277(5.8)\end{aligned}$ \\
\hline $\begin{array}{l}\text { Parity } \\
\quad 1 \\
2 \\
3 \\
4 \\
\geqslant 5\end{array}$ & $\begin{array}{l}202401(23.4) \\
401324(46.5) \\
200802(23.3) \\
4627 \mid(5.4) \\
12509(1.4)\end{array}$ & $\begin{array}{r}15890(28.2) \\
25673(45.5) \\
11612(20.6) \\
2576(4.6) \\
654(1.2)\end{array}$ \\
\hline $\begin{array}{l}\text { Offspring sex in first pregnancy } \\
\text { Male } \\
\text { Female }\end{array}$ & $\begin{array}{l}443529(51.4) \\
419778(48.6)\end{array}$ & $\begin{array}{l}29901(53.0) \\
26504(47.0)\end{array}$ \\
\hline $\begin{array}{l}\text { Birth weight in first pregnancy }(\mathrm{g}) \\
\quad<3000 \\
\quad 3000-4000 \\
\quad \geqslant 4000\end{array}$ & $\begin{array}{l}143408(16.6) \\
597668(69.2) \\
122246(14.2)\end{array}$ & $\begin{array}{r}18417(32.7) \\
30399(53.9) \\
7590(13.5)\end{array}$ \\
\hline $\begin{array}{l}\text { Duration of first pregnancy }{ }^{\mathrm{a}} \text { (weeks) } \\
\quad<37 \\
\quad \geqslant 37\end{array}$ & $\begin{array}{l}50005(5.8) \\
81317(94.2)\end{array}$ & $\begin{array}{r}8704(15.4) \\
47702(84.6)\end{array}$ \\
\hline $\begin{array}{l}\text { Marital status at first birth } \\
\text { Married/cohabiting } \\
\text { Single }\end{array}$ & $\begin{array}{l}719525(83.3) \\
143782(16.7)\end{array}$ & $\begin{array}{r}48266(85.6) \\
8139(14.4)\end{array}$ \\
\hline
\end{tabular}

Abbreviations: $H I P=$ hypertension in pregnancy; $I Q R=$ interquartile range; $P E=$

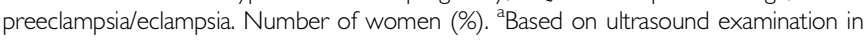
$24 \%$ of the pregnancies and on the first day of the last menstrual period in $76 \%$. offspring was a male (HR $0.80,95 \%$ CI $0.72,0.88$ ) or a female (HR $0.88,95 \%$ CI $0.79,0.97)$, and there was no clear risk difference by offspring sex among women who gave birth after 37 weeks. However, among women with a preterm first birth, the reduced breast cancer risk associated with PE/HIP was restricted to women with a male offspring.

Table 6 shows duration of first pregnancy in relation to breast cancer risk, stratified by PE/HIP status. There was a reduction in risk with increasing duration of first pregnancy, and the inverse association was more pronounced among women with PE/HIP than among normotensive women (HR per week longer duration 0.95 , $95 \%$ CI $0.93,0.98$ and 0.99 , and 95\% CI 0.98, 1.00, respectively). Crude absolute incidence rates among women whose first pregnancy was shorter than 32 weeks were similar, regardless of the PE/HIP status.

In all analyses, adjustment for potentially confounding factors marginally strengthened the associations, compared with models with adjustment for age alone. There was no change in the main results when women with missing information on offspring birth weight and sex, and duration of pregnancy were included in the analyses.

\section{DISCUSSION}

In this prospective study of 919712 women, hypertensive diseases in pregnancy was associated with a reduced risk of breast cancer, of a similar magnitude as previously reported (Vatten et al, 2002a, 2007). The reduced risk was similar for PE/HIP in the first pregnancy, in any pregnancy, and for recurrent PE/HIP, and for breast cancer diagnosed both before and after 50 years of age. The lowest risk was observed for women who developed PE/HIP and had a term or post-term birth, or a child of average birth weight.

Our results correspond to those of most previous studies in reporting a moderately reduced risk (Polednak and Janerich, 1983; Thompson et al, 1989; Troisi et al, 1998; Cohn et al, 2001; Innes and Byers, 2004; Terry et al, 2007), regardless of whether preeclampsia (Polednak and Janerich, 1983; Troisi et al, 1998; Cohn et al, 2001; Innes and Byers, 2004; Terry et al, 2007) or hypertension in pregnancy (Thompson et al, 1989; Troisi et al, 1998; Cohn et al, 2001; Terry et al, 2007) was studied. All but one (Cohn et al, 2001) of those studies had a retrospective design, and the assessment of hypertensive disease in pregnancy was based on patients' recall in some studies (Thompson et al, 1989; Troisi et al, 1998; Terry et al, 2007) and on hospital records in others (Polednak and Janerich, 1983; Cohn et al, 2001; Innes and Byers, 2004). However, in a Swedish registry-based study using prospective data, the investigators found no association for hypertensive

Table 2 Hypertensive diseases in pregnancy (PE/HIP) and breast cancer risk in 9197/2 Norwegian women

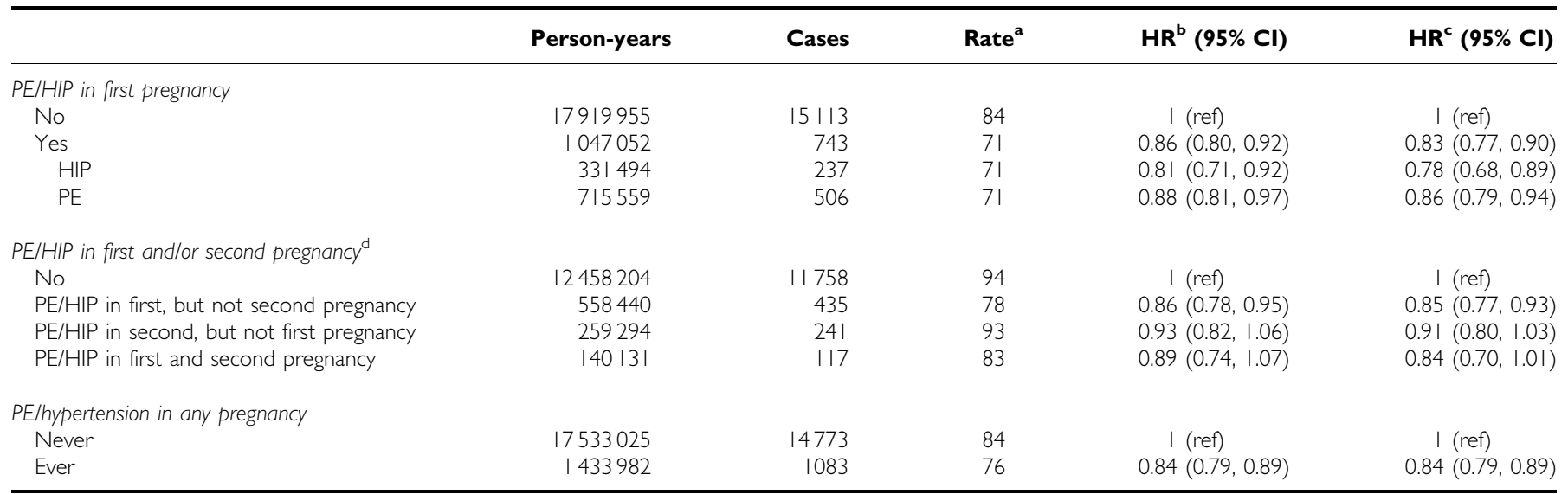

Abbreviations: $\mathrm{Cl}=$ confidence intervals; $\mathrm{HIP}=$ hypertension in pregnancy; $\mathrm{HR}=$ hazard ratio; $\mathrm{PE}=$ preeclampsia/eclampsia. ${ }^{\mathrm{a}} \mathrm{Cases} / \mathrm{I} 00 \mathrm{000}$ person-years, unadjusted. ${ }^{\mathrm{b}} \mathrm{Adj}$ usted for age. 'Adjusted for age, birth cohort, parity, age at first birth, and marital status at first birth. "Women with two or more pregnancies, followed from the date of their second birth. 
Pregnancy hypertension and breast cancer risk

S Opdahl et al

Table 3 Hypertensive diseases in pregnancy (PE/HIP) and breast cancer risk in 919712 Norwegian women, stratified by age

\begin{tabular}{|c|c|c|c|c|c|c|}
\hline & \multicolumn{3}{|c|}{ Premenopausal ( $<\mathbf{5 0}$ years) } & \multicolumn{3}{|c|}{ Postmenopausal ( $\geqslant 50$ years) } \\
\hline \multicolumn{7}{|l|}{$P E / H I P$ in first pregnancy } \\
\hline No & 8013 & 53 & I (ref) & 7038 & 264 & I (ref) \\
\hline Yes & 405 & 45 & $0.84(0.76,0.93)$ & 337 & 228 & $0.83(0.75,0.93)$ \\
\hline HIP & 130 & 46 & $0.81(0.68,0.96)$ & 106 & 206 & $0.75(0.62,0.91)$ \\
\hline PE & 275 & 44 & $0.86(0.76,0.97)$ & 231 & 240 & $0.88(0.77,1.00)$ \\
\hline \multicolumn{7}{|l|}{ PE/hypertension in first and/or second pregnancy ${ }^{c}$} \\
\hline No & 6281 & 61 & I (ref) & 5427 & 255 & I (ref) \\
\hline PE/HIP in first, but not second pregnancy & 237 & 50 & $0.83(0.73,0.94)$ & 197 & 227 & $0.88(0.76,1.01)$ \\
\hline $\mathrm{PE} / \mathrm{HIP}$ in second, but not first pregnancy & 126 & 60 & $0.91(0.76,1.08)$ & 114 & 239 & $0.91(0.75,1.07)$ \\
\hline $\mathrm{PE} / \mathrm{HIP}$ in first and second pregnancy & 69 & 59 & $0.89(0.70,1.13)$ & 48 & 213 & $0.79(0.59,1.08)$ \\
\hline \multicolumn{7}{|l|}{$P E / H I P$ in any pregnancy } \\
\hline Never & 7841 & 52 & I (ref) & $687 \mid$ & 266 & I (ref) \\
\hline
\end{tabular}

Abbreviations: $\mathrm{Cl}=$ confidence intervals; $\mathrm{HIP}=$ hypertension in pregnancy; $\mathrm{HR}=$ hazard ratio; $\mathrm{PE}=$ preeclampsia/eclampsia. ${ }^{\mathrm{a} C} \mathrm{Cases} / \mathrm{I} 00000$ person-years, unadjusted. ${ }^{\mathrm{b}}$ Adjusted for age, birth cohort, parity, age at first birth, and marital status at first birth. 'Women with two or more pregnancies, followed from the date of their second birth in analyses of women $<50$ years, and from age 50 years in analyses of women $\geqslant 50$ years.

Table 4 PE/HIP in first pregnancy and breast cancer risk in 9197/2 Norwegian women, stratified by offspring birth weight and duration of pregnancy

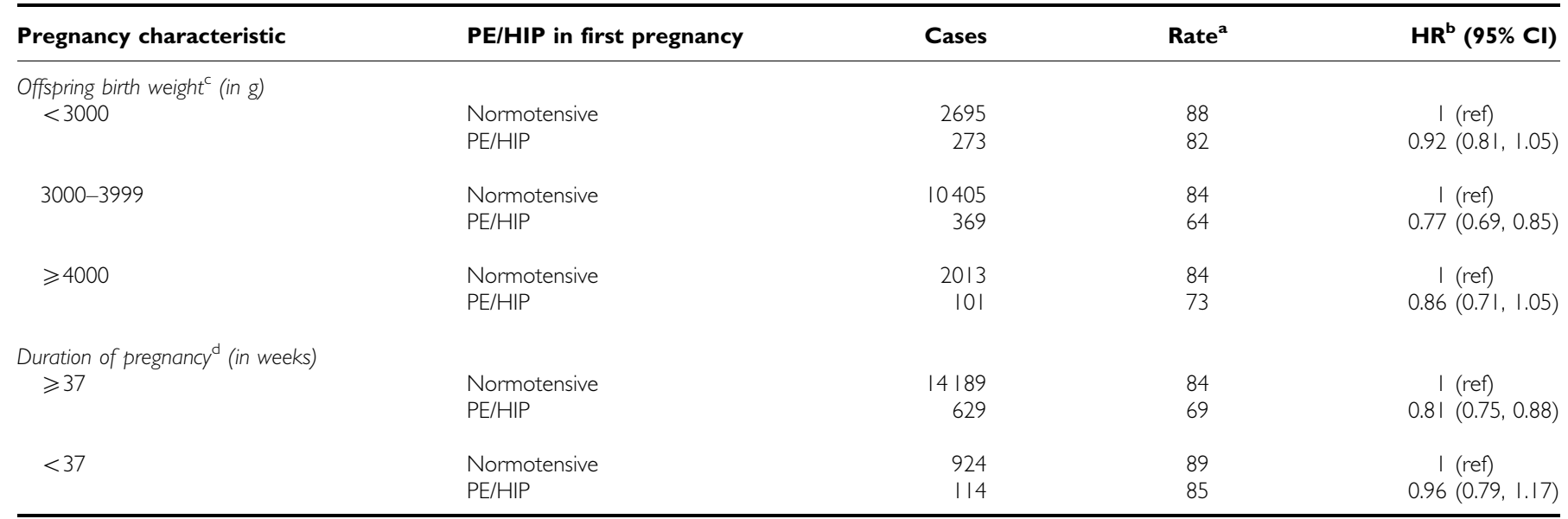

Abbreviations: $\mathrm{Cl}=$ confidence intervals; $\mathrm{HIP}=$ hypertension in pregnancy; $\mathrm{HR}=$ hazard ratio; $\mathrm{PE}=$ preeclampsia/eclampsia. ${ }^{\mathrm{a} C} \mathrm{Cases} / \mathrm{I} 00000$ person-years, unadjusted. ${ }^{\mathrm{b}} \mathrm{Adj}$ usted for age, birth cohort, parity, age at first birth and marital status at first birth. ${ }^{C} P$-value from LR-test of interaction term 0.16 . ${ }^{d} P$-value from LR-test of interaction term 0.09 .

Table 5 PE/HIP in first pregnancy and breast cancer risk in 919712 Norwegian women, stratified by offspring sex

\begin{tabular}{|c|c|c|c|c|c|c|}
\hline & \multicolumn{3}{|c|}{ Male offspring } & \multicolumn{3}{|c|}{ Female offspring } \\
\hline & Cases & Rate $^{\mathbf{a}}$ & $\mathrm{HR}^{\mathrm{b}}(95 \% \mathrm{Cl})$ & Cases & Rate $^{\mathbf{a}}$ & $\operatorname{HR}^{\mathrm{b}}(95 \% \mathrm{Cl})$ \\
\hline \multicolumn{7}{|l|}{$P E / H I P$ in first pregnancy ${ }^{c}$} \\
\hline Yes & 379 & 68 & $0.80(0.72,0.88)$ & 364 & 74 & $0.88(0.79,0.97)$ \\
\hline \multicolumn{7}{|l|}{$P E / H I P$ in first pregnancy } \\
\hline$<37$ weeks and normotensive ${ }^{\mathrm{e}}$ & 511 & 87 & I (ref) & 416 & 91 & I (ref) \\
\hline$<37$ weeks and $\mathrm{PE} / \mathrm{HIP}$ & 53 & 73 & $0.82(0.62,1.09)$ & 61 & 98 & $1.14(0.86,1.49)$ \\
\hline
\end{tabular}

Abbreviations: $\mathrm{Cl}=$ confidence intervals; $\mathrm{HIP}=$ hypertension in pregnancy; $\mathrm{HR}=$ hazard ratio; $\mathrm{PE}=$ preeclampsia/eclampsia. ${ }^{\mathrm{a}} \mathrm{Cases} / \mathrm{I} 00000$ person-years, unadjusted. ${ }^{\mathrm{b}} \mathrm{Adj}$ (j) $\mathrm{usted}$ for age, birth cohort, parity, age at first birth and marital status at first birth. ${ }^{C} P$-value from $L R$-test of interaction term 0.23 . ${ }^{d} P$-value from $L R$-test of interaction term $0.5 I$. ${ }^{e} P$-value from LR-test of interaction term 0.18 . 
Table 6 Duration of first pregnancy and breast cancer risk in 919712 Norwegian women, stratified by PE/HIP status

\begin{tabular}{|c|c|c|c|c|c|c|}
\hline & \multicolumn{3}{|c|}{ Normotensive } & \multicolumn{3}{|c|}{ PE/HIP } \\
\hline & Cases & Rate $^{\mathbf{a}}$ & $\mathrm{HR}^{\mathrm{b}}(95 \% \mathrm{Cl})$ & Cases & Rate $^{\mathbf{a}}$ & $\mathrm{HR}^{\mathrm{b}}(95 \% \mathrm{Cl})$ \\
\hline \multicolumn{7}{|c|}{ Duration of first pregnancy (weeks) } \\
\hline $32-36$ & 724 & 89 & $1.01(0.86,1.18)$ & 93 & 84 & $0.83(0.5 \mathrm{I}, 1.33)$ \\
\hline 37 & 565 & 88 & $0.99(0.84,1.17)$ & 52 & 76 & $0.74(0.45,1.23)$ \\
\hline 38 & 1211 & 85 & $0.96(0.82,1.11)$ & 80 & 69 & $0.68(0.42,1.11)$ \\
\hline$\geqslant 42$ & 2391 & 81 & $0.90(0.78,1.04)$ & 72 & 58 & $0.56(0.34,0.91)$ \\
\hline Per week ${ }^{c}$ & 15113 & 84 & $0.99(0.98,1.00)$ & 743 & 71 & $0.95(0.93,0.98)$ \\
\hline
\end{tabular}

Abbreviations: $\mathrm{Cl}=$ confidence intervals; $\mathrm{HIP}=$ hypertension in pregnancy; HR = hazard ratio; PE $=$ preeclampsia/eclampsia. ${ }^{\mathrm{a} C a s e s} / \mathrm{I} 00000$ person-years, unadjusted. ${ }^{\mathrm{b}} \mathrm{Adjusted}$ for age, birth cohort and parity, age at first birth and marital status at first birth. ${ }^{c} P$-value from LR-test of interaction term 0.22 .

diseases combined, but estimates were not adjusted for other potentially confounding factors (Cnattingius et al, 2005). In two other prospective studies, there was no association of self-reported (Ma et al, 2010) or registry-based (Mogren et al, 2001) preeclampsia with breast cancer risk. In a hospital-based prospective study from Israel (Calderon-Margalit et al, 2009) and in a retrospective study from Italy, based on self-reported data (Talamini et al, 1997), the researchers reported an increased risk of breast cancer associated with preeclampsia and hypertensive disease in pregnancy, respectively. The reasons for the divergence in results between studies are unclear, but may be related to study size, exposure definition, lack of adjustment for potential confounding, genetic factors, or to modification by unmeasured or unknown factors. For simplicity, characteristics and main results of the referred previous studies are summarised in Table 7.

Our study encompassed all women who gave their first birth in Norway during the study period, and information on incident breast cancer was collected prospectively. Therefore, bias in selection or information recall is unlikely. Misclassification of breast cancer diagnoses is most likely negligible, as reporting of cancer to the Cancer Registry of Norway is mandatory by law, and the breast cancer diagnoses were based on pathology reports for $99.9 \%$ of the women for whom a breast cancer diagnosis was reported.

We did not have information on body mass index, which could have confounded the association of hypertensive conditions in pregnancy with breast cancer risk (Nechuta et al, 2010). Overweight and obesity are associated with an increased risk of developing hypertensive diseases during pregnancy (Villar et al, 2006), and a high body mass index during the reproductive years is associated with reduced risk of premenopausal breast cancer (Friedenreich, 2001). For postmenopausal women, overweight is generally associated with an increased risk (Friedenreich, 2001), although there are indications that overweight at a young age may be associated with a modestly reduced risk, of postmenopausal breast cancer (Baer et al, 2010). We found a similar reduction in risk both before and after 50 years of age, which may suggest that the association cannot be fully attributed to confounding by overweight. The results of one study indicated that adjustment for body mass index may attenuate the association of hypertensive diseases in pregnancy with breast cancer risk among premenopausal, but not in postmenopausal women (Terry et al, 2007). However, in most studies that have been able to evaluate the possible confounding by body mass index, estimates have remained unchanged after adjustment (Thompson et al, 1989; Talamini et al, 1997; Troisi et al, 1998; Ma et al, 2010). Other potentially confounding factors include insulin resistance and diabetes mellitus, which are strongly related to the risk of preeclampsia (Sohlberg et al, 2012) and may also be related to breast cancer risk (Bjorge et al, 2010).
The accuracy of the exposure in our study has not been validated The diagnostic criteria for preeclampsia have changed over time and are still debated (Trogstad et al, 2011). Although some misclassification may have occurred, it is likely to be non-differential with respect to future breast cancer diagnosis, and its effect would lead to conservative estimates. We had no direct information on menopausal status, but used 50 years of age as a crude indicator. In addition, the cohort is still relatively young. This could have obscured potential differences in association by menopausal status, but the similarly reduced risks for women 60 years or older suggest that the association was not likely to be modified by menopausal status. We used duration of pregnancy as an indicator for the severity of hypertensive disease in pregnancy. Because of the induction of labour in women with a severe hypertensive disease, duration of pregnancy may be regarded as an intermediate variable, and we cannot exclude the possibility that this may introduce a bias (Cole and Hernan, 2002). However, duration of pregnancy is not strongly related to breast cancer risk, and therefore, the potential bias would be negligible. Finally, our results should be interpreted considering that multiple tests were carried out, and although these were related, chance findings cannot be ruled out.

There is an inverse association of parity with breast cancer risk, where each additional pregnancy confers additional protection. This effect has been attributed to the repeated exposure to pregnancy hormones (Kelsey et al, 1993). If pregnancy hypertensive diseases influence breast cancer risk through pregnancyspecific events, such as altering the hormonal milieu compared with that of normotensive pregnancies (Innes and Byers, 1999; Tamimi et al, 2003), one might expect that women who experience more than one hypertensive pregnancy would be at particularly low risk. However, the risk reduction among women with recurrent hypertensive disease in pregnancy was not particularly strong, in contrast to reports by others (Terry et al, 2007).

Possible differences in the association by offspring sex were weaker in this analysis than previously reported (Vatten et al, 2007). In preeclampsia, the duration of pregnancy tends to be longer if the fetus is a male (Vatten and Skjaerven, 2004), but it is unclear whether this puzzling phenomenon could disturb the sexspecific analyses of hypertensive diseases and breast cancer risk.

The inverse association of duration of first pregnancy with breast cancer risk was slightly attenuated compared with what has previously been reported (Vatten et al, 2002b). A possible impact of duration of pregnancy on breast cancer risk has been attributed to increased differentiation of breast tissue in women with longer exposure to pregnancy hormones (Nechuta et al, 2010). In our study, the association was particularly strong among women who had a hypertensive disease in their first pregnancy. Preeclampsia is thought to originate from an abnormal placentation and/or an abnormal maternal response to the pregnancy (Trogstad et al, 2011). There are indications that early preeclampsia may be more 
Table 7 Selected characteristics and main results of previous studies of hypertensive diseases in pregnancy and breast cancer risk ${ }^{\mathrm{a}}$

\begin{tabular}{|c|c|c|c|c|c|c|}
\hline Study and location & $\begin{array}{l}\text { Cases/ } \\
\text { controls }\end{array}$ & $\begin{array}{l}\text { Age at } \\
\text { diagnosis } \\
\text { (years) }\end{array}$ & $\begin{array}{l}\text { Exposure } \\
\text { assessment }\end{array}$ & $\begin{array}{l}\text { Exposure } \\
\left.\text { (prevalence }{ }^{b}, \%\right)\end{array}$ & $\begin{array}{l}\text { HR/RR/OR } \\
\text { (95\% CI) }\end{array}$ & Covariates \\
\hline \multicolumn{7}{|l|}{ Cohort studies } \\
\hline \multirow{2}{*}{$\begin{array}{l}\text { Cohn et al, 200I, } \\
\text { United States }\end{array}$} & \multirow{2}{*}{$\begin{array}{l}146 / \\
3658\end{array}$} & \multirow[t]{2}{*}{ Mean 54.2} & \multirow[t]{2}{*}{ Birth records } & \multirow{2}{*}{$\begin{array}{l}P \text { in any pregnancy } \\
(N R) \\
\text { Blood pressure } \\
\text { increase QI vs Q4 } \\
(N R)\end{array}$} & $0.60^{c}$ & \multirow{2}{*}{$\begin{array}{l}\text { Age } \\
\text { Age, birth year, parity, age at first birth, } \\
\text { maternal weight gain }\end{array}$} \\
\hline & & & & & $0.50(0.31,0.82)$ & \\
\hline $\begin{array}{l}\text { Mogren et al, 200I, } \\
\text { Sweden }\end{array}$ & $\begin{array}{l}870 / \\
40081\end{array}$ & $\begin{array}{l}\text { Range } 25-71 \\
\text { Median } 48\end{array}$ & $\begin{array}{l}\text { Swedish Birth } \\
\text { Register (ICD-8, } \\
\text { ICD-9) }\end{array}$ & $\begin{array}{l}\mathrm{P} / \mathrm{HIP} \text { in any } \\
\text { pregnancy }(8.3)\end{array}$ & $\begin{array}{l}\text { No association } \\
\text { (estimate NR) }\end{array}$ & $N R$ \\
\hline $\begin{array}{l}\text { Cnattingius et al, } 2005 \text {, } \\
\text { Sweden }\end{array}$ & $\begin{array}{l}2216 / \\
311803\end{array}$ & $\begin{array}{l}95 \% \text { of cases } \\
<50\end{array}$ & $\begin{array}{l}\text { Swedish Birth } \\
\text { Register (ICD-8, } \\
\text { ICD-9) }\end{array}$ & $\begin{array}{l}\mathrm{PE} / \mathrm{HIP} \text { in first } \\
\text { pregnancy }(6.8)\end{array}$ & $1.05^{c}$ & - \\
\hline $\begin{array}{l}\text { Vatten et al, 2002a, } \\
\text { Norway }\end{array}$ & $\begin{array}{l}5474 / \\
689183\end{array}$ & Range $<30-80$ & $\begin{array}{l}\text { Medical Birth } \\
\text { Registry of } \\
\text { Norway (ICD-8) }\end{array}$ & $\begin{array}{l}\mathrm{PE} / \mathrm{HIP} \text { in first } \\
\text { pregnancy }(6.2)\end{array}$ & $0.8 \mid(0.7|, 0.9|)$ & $\begin{array}{l}\text { Age, year of diagnosis, age at first birth, } \\
\text { and parity }\end{array}$ \\
\hline $\begin{array}{l}\text { Vatten et al, } 2007, \\
\text { Norway }\end{array}$ & $\begin{array}{l}9160 / \\
691846\end{array}$ & Range $<30-84$ & $\begin{array}{l}\text { Medical Birth } \\
\text { Registry of } \\
\text { Norway (ICD-8) }\end{array}$ & $\begin{array}{l}\mathrm{PE} / \mathrm{HIP} \text { in first } \\
\text { pregnancy }(6.2)\end{array}$ & $0.86(0.78,0.94)$ & $\begin{array}{l}\text { Age, age at first birth, duration of } \\
\text { pregnancy, parity, marital status, and } \\
\text { offspring sex }\end{array}$ \\
\hline $\begin{array}{l}\text { Calderon-Margalit et al, } 2009 \text {, } \\
\text { Israel }\end{array}$ & $\begin{array}{l}2024 / \\
35903\end{array}$ & $N R$ & Birth records & $\begin{array}{l}\mathrm{P} \text { in any pregnancy } \\
(2.9)\end{array}$ & $1.37(1.06,1.78)$ & Age at first birth and parity \\
\hline $\begin{array}{l}\text { Ma et al, } 2010 \\
\text { United States }\end{array}$ & $\begin{array}{l}1768 / \\
29691\end{array}$ & $\begin{array}{l}\text { Postmenopausal } \\
<80\end{array}$ & Self-reported & $\begin{array}{l}\mathrm{P} \text { in last pregnancy } \\
(\mathrm{NR})\end{array}$ & & $\begin{array}{l}\text { Age, race, family history of breast } \\
\text { cancer, age at menarche, hormone }\end{array}$ \\
\hline & & & & $\begin{array}{l}P \text { in other pregnancy } \\
(N R)\end{array}$ & $0.77(0.58,1.02)$ & $\begin{array}{l}\text { therapy use, body mass index, and } \\
\text { parity }\end{array}$ \\
\hline \multicolumn{7}{|l|}{ Case-control studies } \\
\hline $\begin{array}{l}\text { Polednak and Janerich, } 1983, \\
\text { United States }\end{array}$ & $\begin{array}{l}314 / \\
628\end{array}$ & All cases $<45$ & Birth records & $\begin{array}{l}\text { PE in first pregnancy } \\
(2.4)\end{array}$ & $0.28(0.08,1.00)$ & $\begin{array}{l}\text { Location and time of birth (matched), } \\
\text { age at first birth }\end{array}$ \\
\hline $\begin{array}{l}\text { Thompson et al, } 1989, \\
\text { United States }\end{array}$ & $\begin{array}{l}4668 / \\
4635\end{array}$ & Range 20-54 & Self-reported & $\begin{array}{l}\text { HT before or during } \\
\text { last pregnancy }(4.9)\end{array}$ & $0.73(0.59,0.92)$ & $\begin{array}{l}\text { Age and geographic region (matched), } \\
\text { parity, age at first term pregnancy, and } \\
\text { total duration of breast feeding. Body } \\
\text { mass (not included in final model) }\end{array}$ \\
\hline $\begin{array}{l}\text { Talamini et al, } 1997, \\
\text { Italy }\end{array}$ & $\begin{array}{l}2569 / \\
2588\end{array}$ & $\begin{array}{l}\text { Range } 23-74 \\
\text { Median } 55\end{array}$ & Self-reported & $\begin{array}{l}\text { HIP in any pregnancy } \\
(0.5)\end{array}$ & $1.8(1.0,3.4)$ & $\begin{array}{l}\text { Study area, age, education, parity, body } \\
\text { mass index, and menopausal status }\end{array}$ \\
\hline \multirow[t]{2}{*}{$\begin{array}{l}\text { Troisi et al, 1998, } \\
\text { United States }\end{array}$} & \multirow[t]{2}{*}{$\begin{array}{l}1236 / \\
1162\end{array}$} & \multirow[t]{2}{*}{ Range 20-44 } & \multirow[t]{2}{*}{ Self-reported } & \multirow{2}{*}{$\begin{array}{l}\text { PE in any pregnancy } \\
(10.4) \\
\text { HIP in any pregnancy } \\
(13.8)\end{array}$} & & \multirow{2}{*}{$\begin{array}{l}\text { Age and site (matched), race, parity, } \\
\text { age at first birth, body mass index, and } \\
\text { menopausal status }\end{array}$} \\
\hline & & & & & $0.94(0.73,1.2)$ & \\
\hline $\begin{array}{l}\text { Innes and Byers, 2004, } \\
\text { United States }\end{array}$ & $\begin{array}{l}2404 / \\
9638\end{array}$ & $\begin{array}{l}\text { Range } 22-55 \\
\text { Mean } 37.6\end{array}$ & Birth records & $\begin{array}{l}P \text { in first pregnancy } \\
(4.1)\end{array}$ & $0.86(0.67,1.12)$ & $\begin{array}{l}\text { County and date of delivery (matched), } \\
\text { age, and age at first birth }\end{array}$ \\
\hline $\begin{array}{l}\text { Terry et al, 2007, } \\
\text { United States }\end{array}$ & $\begin{array}{l}1303 / \\
1374\end{array}$ & Range 20-98 & Self-reported & $\begin{array}{l}\mathrm{PE} / \mathrm{HIP} \text { in any } \\
\text { pregnancy }(13.6)\end{array}$ & $0.71(0.55,0.93)$ & $\begin{array}{l}\text { Age, age at first birth, body mass index, } \\
\text { parity, smoking status, menopausal } \\
\text { status, age at menarche, lactation, family } \\
\text { history of breast cancer, ethnicity, and } \\
\text { education }\end{array}$ \\
\hline
\end{tabular}

Abbreviations: $\mathrm{Cl}=$ confidence interval; $\mathrm{HIP}=$ hypertension in pregnancy; $\mathrm{HR}=$ hazard ratio; $\mathrm{HT}=$ hypertension; $\mathrm{ICD}=$ International $\mathrm{Classification}$ of Diseases; $\mathrm{NR}=$ not reported; $\mathrm{OR}=$ odds ratio; $\mathrm{P}=$ preeclampsia; $\mathrm{PE}=$ preeclampsia/eclampsia; $\mathrm{Q}$ I = lowest quartile; $\mathrm{Q} 4=$ highest quartile; $\mathrm{RR}=$ relative risk. ${ }^{\mathrm{a}} \mathrm{Only}$ studies referred to in the discussion are included. ${ }^{b}$ Among all participants in cohort studies and among controls only in case-control studies. ${ }^{c}$ Only incidence rates reported.

closely associated with placental dysfunction than preeclampsia detected at term, and that term preeclampsia may be more strongly related to maternal metabolic factors (Huppertz, 2008; Valensise et al, 2008), such as overweight and obesity (Sohlberg et al, 2012). Furthermore, risk factors for preeclampsia are associated with patterns of blood pressure change in normotensive pregnancies similar to those seen in preeclampsia (Macdonald-Wallis et al, 2011), and gestational hypertension and preeclampsia may be closely related conditions (Villar et al, 2006). The lower breast cancer risk observed for women who experienced hypertension or preeclampsia in their first pregnancy and had a term or post-term birth may indicate that maternal metabolic factors may have an important role.
In conclusion, women who experience hypertensive diseases in pregnancy are at reduced risk of breast cancer. Further research is needed to clarify whether this association can be attributed to pregnancy-specific events or to underlying biological traits. A better understanding of how hypertensive diseases in pregnancy influence breast cancer risk may be useful for our understanding of breast cancer development.

\section{ACKNOWLEDGEMENTS}

The study was financially supported by the Norwegian Research Council. We thank the Cancer Registry of Norway and the Medical Birth Registry of Norway for providing the data. 


\section{REFERENCES}

Backe B (1992) Norwegian experiences. Competence of the providers and compliance to the treatment program for antenatal care in Norway. Int $J$ Technol Assess Health Care 8(Suppl 1): 13-19

Baer HJ, Tworoger SS, Hankinson SE, Willett WC (2010) Body fatness at young ages and risk of breast cancer throughout life. Am J Epidemiol 171(11): 1183-1194

Bjorge T, Lukanova A, Jonsson H, Tretli S, Ulmer H, Manjer J, Stocks T, Selmer R, Nagel G, Almquist M, Concin H, Hallmans G, Haggstrom C, Stattin P, Engeland A (2010) Metabolic syndrome and breast cancer in the me-can (metabolic syndrome and cancer) project. Cancer Epidemiol Biomarkers Prev 19(7): 1737-1745

Britt K, Ashworth A, Smalley M (2007) Pregnancy and the risk of breast cancer. Endocr Relat Cancer 14(4): 907-933

Calderon-Margalit R, Friedlander Y, Yanetz R, Deutsch L, Perrin MC, Kleinhaus K, Tiram E, Harlap S, Paltiel O (2009) Preeclampsia and subsequent risk of cancer: update from the Jerusalem Perinatal Study. Am J Obstet Gynecol 200(1): 63. e1-63. e5

Cnattingius S, Torrang A, Ekbom A, Granath F, Petersson G, Lambe M (2005) Pregnancy characteristics and maternal risk of breast cancer. JAMA 294(19): 2474-2480

Cohn BA, Cirillo PM, Christianson RE, van den Berg BJ, Siiteri PK (2001) Placental characteristics and reduced risk of maternal breast cancer. J Natl Cancer Inst 93(15): 1133-1140

Cole SR, Hernan MA (2002) Fallibility in estimating direct effects. Int J Epidemiol 31(1): 163-165

Friedenreich CM (2001) Review of anthropometric factors and breast cancer risk. Eur J Cancer Prev 10(1): 15-32

Huppertz B (2008) Placental origins of preeclampsia: challenging the current hypothesis. Hypertension 51(4): 970-975

Innes KE, Byers TE (1999) Preeclampsia and breast cancer risk. Epidemiology 10(6): 722-732

Innes KE, Byers TE (2004) First pregnancy characteristics and subsequent breast cancer risk among young women. Int $\mathrm{J}$ Cancer 112(2): 306-311

Kelsey JL, Gammon MD, John EM (1993) Reproductive factors and breast cancer. Epidemiol Rev 15(1): 36-47

Larsen IK, Småstuen M, Parkin DM, Bray F (2007) Data Quality at the Cancer Registry of Norway. Cancer in Norway 2006 - Cancer Incidence, Mortality, Survival and Prevalence in Norway. Cancer Registry of Norway: Oslo

Ma H, Henderson KD, Sullivan-Halley J, Duan L, Marshall SF, Ursin G, Horn-Ross PL, Largent J, Deapen DM, Lacey Jr. JV, Bernstein L (2010) Pregnancy-related factors and the risk of breast carcinoma in situ and invasive breast cancer among postmenopausal women in the California Teachers Study cohort. Breast Cancer Res 12(3): R35

Macdonald-Wallis C, Tilling K, Fraser A, Nelson SM, Lawlor DA (2011) Established preeclampsia risk factors are related to patterns of blood pressure change in normal term pregnancy: findings from the Avon Longitudinal Study of Parents and Children. J Hypertens 29(9): 1703-1711

Mogren I, Stenlund H, Hogberg U (2001) Long-term impact of reproductive factors on the risk of cervical, endometrial, ovarian and breast cancer. Acta Oncol 40(7): 849-854
Nechuta S, Paneth N, Velie EM (2010) Pregnancy characteristics and maternal breast cancer risk: a review of the epidemiologic literature. Cancer Causes Control 21(7): 967-989

NIPH (2009) Medisinsk fødselsregisters variabeldefinisjon (in Norwegian). Norwegian Institute of Public Health website. Oslo. Accessed 27 March 2012. Available from http://www.fhi.no/dokumenter/ 8f2fb56c54.pdfhttp://www.fhi.no/dokumenter/46087a62ea.pdf

Polednak AP, Janerich DT (1983) Characteristics of first pregnancy in relation to early breast cancer. A case-control study. J Reprod Med 28(5): 314-318

Sohlberg S, Stephansson O, Cnattingius S, Wikstrom AK (2012) Maternal body mass index, height, and risks of preeclampsia. Am J Hypertens 25(1): 120-125

Talamini R, Franceschi S, Favero A, Negri E, Parazzini F, La Vecchia C (1997) Selected medical conditions and risk of breast cancer. Br J Cancer 75(11): 1699-1703

Tamimi R, Lagiou P, Vatten LJ, Mucci L, Trichopoulos D, Hellerstein S, Ekbom A, Adami HO, Hsieh CC (2003) Pregnancy hormones, preeclampsia, and implications for breast cancer risk in the offspring. Cancer Epidemiol Biomarkers Prev 12(7): 647-650

Terry MB, Perrin M, Salafia CM, Zhang FF, Neugut AI, Teitelbaum SL, Britton J, Gammon MD (2007) Preeclampsia, pregnancy-related hypertension, and breast cancer risk. Am J Epidemiol 165(9): 1007-1014

Thompson WD, Jacobson HI, Negrini B, Janerich DT (1989) Hypertension, pregnancy, and risk of breast cancer. J Natl Cancer Inst 81(20): 1571-1574

Trogstad L, Magnus P, Stoltenberg C (2011) Pre-eclampsia: Risk factors and causal models. Best Pract Res Clin Obstet Gynaecol 25(3): 329-342

Troisi R, Innes KE, Roberts JM, Hoover RN (2007) Preeclampsia and maternal breast cancer risk by offspring gender: do elevated androgen concentrations play a role? Br J Cancer 97(5): 688-690

Troisi R, Weiss HA, Hoover RN, Potischman N, Swanson CA, Brogan DR, Coates RJ, Gammon MD, Malone KE, Daling JR, Brinton LA (1998) Pregnancy characteristics and maternal risk of breast cancer. Epidemiology 9(6): 641-647

Valensise H, Vasapollo B, Gagliardi G, Novelli GP (2008) Early and late preeclampsia: two different maternal hemodynamic states in the latent phase of the disease. Hypertension 52(5): 873-880

Vatten LJ, Forman MR, Nilsen TI, Barrett JC, Romundstad PR (2007) The negative association between pre-eclampsia and breast cancer risk may depend on the offspring's gender. Br J Cancer 96(9): 1436-1438

Vatten LJ, Romundstad PR, Trichopoulos D, Skjaerven R (2002a) Preeclampsia in pregnancy and subsequent risk for breast cancer. $\mathrm{Br} J$ Cancer 87(9): 971-973

Vatten LJ, Romundstad PR, Trichopoulos D, Skjaerven R (2002b) Pregnancy related protection against breast cancer depends on length of gestation. Br J Cancer 87(3): 289-290

Vatten LJ, Skjaerven R (2004) Offspring sex and pregnancy outcome by length of gestation. Early Hum Dev 76(1): 47-54

Villar J, Carroli G, Wojdyla D, Abalos E, Giordano D, Ba'aqeel H, Farnot U, Bergsjo P, Bakketeig L, Lumbiganon P, Campodonico L, Al-Mazrou Y, Lindheimer M, Kramer M (2006) Preeclampsia, gestational hypertension and intrauterine growth restriction, related or independent conditions? Am J Obstet Gynecol 194(4): 921-931

This work is published under the standard license to publish agreement. After 12 months the work will become freely available and the license terms will switch to a Creative Commons Attribution-NonCommercial-Share Alike 3.0 Unported License. 